\title{
The Need of Species Distribution Models Metadata: Using Species Distribution Model to Address Decision Making on Climate Change
}

\author{
Wilian França Costa ${ }^{\ddagger, \S, \mid}$, Leonardo Miranda ${ }^{\ddagger}$, Rafael Cabral Borges ${ }^{\ddagger, \pi}$, Antonio Mauro Saraiva ${ }^{\S}$, Vera \\ Lucia Imperatriz-Fonseca§,, , Tereza Cristina Giannini ${ }^{\ddagger}, \mathbb{\pi}$ \\ ‡ Instituto Tecnológico Vale, Belém, Brazil \\ § Universidade de São Paulo, São Paulo, Brazil \\ | Universidade Presbiteriana Mackenzie, São Paulo, Brazil \\ I Universidade Federal do Pará, Belém, Brazil
}

Corresponding author: Wilian França Costa (wilianfc@gmail.com)

Received: 03 Apr 2018| Published: 21 May 2018

Citation: Costa W, Miranda L, Borges R, Saraiva A, Imperatriz-Fonseca V, Giannini T (2018) The Need of

Species Distribution Models Metadata: Using Species Distribution Model to Address Decision Making on Climate

Change. Biodiversity Information Science and Standards 2: e25478. https://doi.org/10.3897/biss.2.25478

\section{Abstract}

Anthropogenic-induced climate change has already altered the conditions to which species have adapted locally, and consequently, shifts of occurrence areas have been previously reported (Chen et al. 2011). Anticipating the results of climate change is urgent, and using these results efficiently to guide decision-making can help to build strategies to protect species from those changes. Therefore, our objective is to propose the use of climate change impact assessments, obtained through species distribution models (SDMs), to guide decision making. The emphasis will be on data that could help determine the potentially vulnerable species and the priority areas, which could act as climate refuges, as well as wildlife corridors. SDMs are based on species occurrence points, available mainly from biological collections and observations (Franklin 2010). When combined with geospatially explicit layers of abiotic or biotic data (e. g. temperature, precipitation, land use), which defines the ecological requirements of species under study, it can generate species distribution models. These models are projected in the form of maps indicating areas where the species can find the most suitable habitats and, therefore, where one can 
most likely find them. To support public policies decision, the generation of robust and reliable model is an important factor. A minimum number of six occurrence points is a mandatory requirement, with non-overlapping area as a filter criteria. Unfortunatelly, in Brasil, as well as in Latin America in general, this type of data is scarce.

Thus, with SDMs, four types of decision making information data regarding priority species and areas could be obtained (Fig. 1).

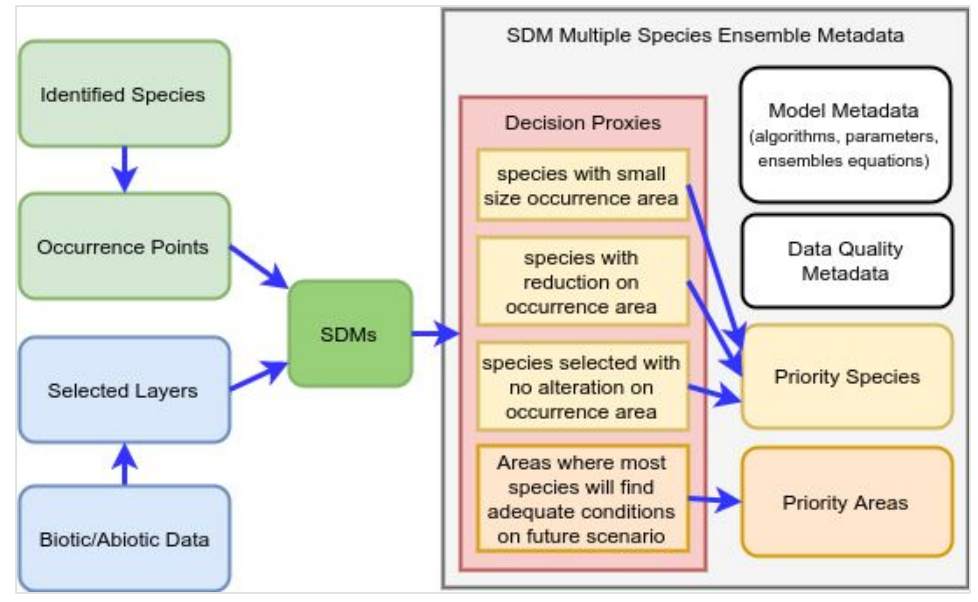

Figure 1.

Priority species and areas, SDM metadata, and proposed decision information proxies on climate change scenarios.

1. Size of potential occurrence areas: species that have a small area of occurrence are potentially vulnerable, since they present endemism, usually living in restricted environmental conditions. In this case, any small change in environmental conditions can result in the extinction of the impacted species. Thus, this region needs to be protected.

2. Difference between current and future area: species presenting the most significant reduction in potential areas should be prioritized by decision-makers. This measurement could be used as an indication of vulnerability.

3. Even species that have no predicted area reduction or an increase could be prioritized in management programs due to its role in the complex interaction networks of ecosystem services, such as pollinators, seed dispersers or disease control. These species could be more resilient to network interaction changes due climate, and possibly are better able to provide their services in the extreme unfavorable climate scenarios.

4. Areas that maintain higher species diversity in future scenarios: their protection could be prioritized in restoration and conservation programs. Especially in cases involving multiple species, those areas could be considered as climate refuges by decision-makers. Additionally, for the reconstruction and use of SDM published in peer-reviewed journals, it is necessary that all pieces of information about models, 
its generation, ensemble methods, data cleaning and data quality criteria applied should be available.

The availability of the four above mentioned types of information can help on decisionmaking strategies aiming the protection of priority species and areas. In conclusion, SDMs present essential information about the present and future impacts of projected climate change and their derived data could be preserved using a standard controlled vocabulary.

\section{Keywords}

Biodiversity, Metadata, Decision Proxy, Climate Change, SDM, Species Distribution Model, Darwin Core

\section{Presenting author}

Wilian França Costa

\section{Funding program}

We are grateful to National Council for Scientific and Technological Development (CNPq) for financial support (proc. 446167/2015-0, 381626/2016-4 and 380277/2018-2).

\section{References}

- Chen I-, Hill JK, Ohlemuller R, Roy DB, Thomas CD (2011) Rapid Range Shifts of Species Associated with High Levels of Climate Warming. Science 333 (6045): 1024-1026. https://doi.org/10.1126/science.1206432

- $\quad$ Franklin J (2010) Mapping Species Distributions: Spatial Inference and Prediction. 1은 ed. Cambridge University Press, Cambridge, New York, 340 pp. [ISBN 978-0-521-70002-3] 